\title{
Serum neopterin levels in patients with replicative and nonreplicative HBV carriers Ilknur Kaleli' ${ }^{1}$, Melek Demir*1, Nural Cevahir ${ }^{1}$, Mustafa Yılmaz ${ }^{2}$ and Suleyman Demir ${ }^{3}$
}

\author{
Address: ${ }^{1}$ Department of Microbiology, Pamukkale University Medical Faculty, Denizli, Turkey, ${ }^{2}$ Department of Gastroenterology, Pamukkale \\ University Medical Faculty, Denizli, Turkey and ${ }^{3}$ Department of Biochemistry, Pamukkale University Medical Faculty, Denizli, Turkey \\ Email: Ilknur Kaleli - ikaleli@pau.edu.tr; Melek Demir* - mdemir@pau.edu.tr; Nural Cevahir - cevahir@pau.edu.tr; \\ Mustafa Yllmaz - myilmaz@pau.edu.tr; Suleyman Demir - suleyman@pau.edu.tr \\ * Corresponding author
}

Published: 31 October 2006

BMC Infectious Diseases 2006, 6:157 doi:10.1186/147/-2334-6-157

This article is available from: http://www.biomedcentral.com/I47I-2334/6/157

(c) 2006 Kaleli et al; licensee BioMed Central Ltd.

This is an Open Access article distributed under the terms of the Creative Commons Attribution License (http://creativecommons.org/licenses/by/2.0), which permits unrestricted use, distribution, and reproduction in any medium, provided the original work is properly cited.

\begin{abstract}
Background: Infection by hepatitis B virus (HBV) causes complicated biochemical, immunological and histological changes in host immune response against the virus which can be specific or nonspecific. Recent attention has focused on neopterin as a marker for the activation of cell mediated immunity. The aim of this study was to define the pattern of neopterin levels in replicative and nonreplicative HBV carriers.
\end{abstract}

Methods: Thirty HBV replicative carriers and 25 nonreplicative HBV carriers and 30 healthy adult patients were included this study. Hepatitis markers were determined by commercial kit based on chemilumminesans assay. HBV DNA was quantified by hybrid capture system. Serum neopterin levels were measured by the method of competitive enzyme-linked immunosorbent assay. Results were expressed as mean \pm SD and ranges.

Results: In the nonreplicative group, except for one patient, all the patients' $\mathrm{HBeAg}$ were negative and anti-HBe were positive. That particular patient was $\mathrm{HBeAg}$ positive and anti-HBe negative. In the replicative group, 23 out of 30 patients have positive $\mathrm{HBeAg}$ and negative anti-HBe; 7 out of 30 patients have negative $\mathrm{HBeAg}$ and positive anti-HBe. Serum neopterin concentrations were $14.5 \pm$ $10.0(4.2-4 \mathrm{I}) \mathrm{nmol} / \mathrm{L}$ in replicative HBV carriers, $8.9 \pm 4.3(2 . \mathrm{I}-22) \mathrm{nmol} / \mathrm{L}$ in nonreplicative HBV carriers and $7.1 \pm 2.2(4.0-12) \mathrm{nmol} / \mathrm{L}$ in the control group. Serum neopterin levels and the rates of abnormal serum neopterin levels in the replicative group were higher than the control group $(P$ $<0.01$ and $P<0.05$ ). In the nonreplicative group, serum neopterin levels were not different from those of control. There was a difference between replicative and nonreplicative groups in the respect of neopterin levels.

Conclusion: In the hepatitis B infected carriers, elevated neopterin levels may be an indicator of the presence of replication. 


\section{Background}

Hepatitis B virus (HBV) infection is a worldwide health problem. The clinical consequences of hepatitis $\mathrm{B}$ virus infection are extremely variable, including clinical syndromes such as fulminant, acute and chronic hepatitis, hepatocellular carcinoma, and the asymptomatic carrier state [1]. Infection by hepatitis B virus causes complicated biochemical, immunological and histological changes in host immune response against virus can be specific or nonspecific. Nonspecific response occurs via cytokines or other substance.

Neopterin is a pyrazino-pyrimidine derivative, namely 2 amino 4-hydroxy-(1',2',3' trihydroxypropyl) pteridine. Biosynthetically neopterin derives from guanosine triphosphate [2]. Neopterin is produced by activated macrophages, in response to interferon-gamma derived from activated T cell. Recent attention has focused on neopterin as a marker for the activation of cell mediated immunity [3]. Elevated neopterin levels in serum and urine have been reported in several acute and chronic infections, allograft rejection, autoimmune and malignant diseases [2,4-7].

In some viral infections neopterin concentration increases during the incubation period, shows a pronounced peak during clinical symptoms and sharply decreases and normalizes during the period of convalences, when neutralizing antibody titers become measurable in the circulation [2].

The aim of this study is to define the pattern of neopterin levels in replicative and nonreplicative HBV carriers.

\section{Methods \\ Patients}

This study included 55 patients infected with HBV for more than 6 months and 30 healthy adult subjects as a control group. All patients gave verbally informed consent to participate in the study. A total of 30 HBV DNA (+) patients were between the age of 13 and 73 years in the replicative group, 25 HBV DNA (-) patients between 20 and 71 were included in the nonreplicative group. The average age of 13 female and 17 male individuals in the replicative group were $40.8 \pm 15.3$ (13-73). In the nonreplicative group, the average age of 10 female and 15 male individuals was $42.8 \pm 13.4(20-71)$. There are 30 health subjects in the control group consisted of 12 females and 18 male subjects. The average age of controls was $44.1 \pm 13.6(21-68)$ years. The groups showed no significant differences in age and sex. The diagnostic criterias for HBV infection were sero-positivity for hepatitis B surface antigen (HBsAg), lack of anti-hepatitis B surface antibodies (anti HBs) and presence of anticore IgG antibodies (anti-HBc). If serum HBV DNA levels was higher than 5 $\mathrm{pg} / \mathrm{ml}$ by hybrid capture system, the patients were considered as HBV replicative carriers $[8,9]$. Of the 55 patients, 30 were HBV replicative carriers, 25 were nonreplicative carriers when serum HBV-DNA undetectable by hybrid capture system.

The control group included 30 healthy individuals without HBV infection (HBsAg negative, antiHBs negative and anti $\mathrm{HBC}$ IgG negative). All patient and controls were without hepatitis C, hepatitis D, Human immunodeficiency virus (HIV) infections and systemic bacterial or fungal infection and autoimmune diseases. Other causes of liver disease such as alcohol consumption and autoimmune hepatitis were excluded.

\section{Procedures}

Viral markers (Access Beckman Coulter-Biorad, USA) and biochemical parameters Synchron LX20, Beckman Coulter, Brea, CA, USA) were determined by commercial kits. HBV DNA was quantified by hybrid capture system (Digene Diagnostic MD, USA), according to the manufacturer's instruction.

\section{Serum neopterin levels}

Serum neopterin levels were measured following the basic principle of competitive enzyme-linked immunosorbent assay (Neopterin ELISA, Immuno Biological Laboratories, Hamburg, Germany): the competition between a peroxidase-conjugated and nonconjugated antigen for a fixed number of antibody binding sites (rabbit anti-neopterin). The peroxidase-conjugated antigen-antibody complexes bind to the wells of the microtiter strips, which are coated with a goat anti-rabbit antibody. Unbound antigen was removed by washing. After the substrate reaction the optical density was measured at $450 \mathrm{~nm}$. Quantification of the samples were estimated by comparing the enzymatic activity of the samples with a response curve prepared by using standards ranging 0 to $111 \mathrm{nmol} / \mathrm{L}$. Results were expressed as mean \pm SD and ranges. Serum specimens were stored at $-20^{\circ} \mathrm{C}$ in the dark until the assay time.

\section{Statistical analysis}

For statistical analysis, Kruskal Wallis and Bonferroni post-hoc tests were used. A p value of $<0.05$ was considered significant.

\section{Results}

The means of serum neopterin concentrations were $14.5 \pm$ 10.0 (median: 11.5 ranged $4.2-41) \mathrm{nmol} / \mathrm{L}$ in replicative HBV carriers, $8.9 \pm 4.3$ (median: 8.0 ranged 2.1-22) $\mathrm{nmol} / \mathrm{L}$ in nonreplicative HBV carriers and $7.1 \pm 2.2$ (median: 7.5 ranged 4.0-12) nmol/L in the control group. The difference between the replicative, nonreplicative and control was statistically significant $(P<0.05)$. In the replicative carriers neopterin levels (Table 1 ) and rates (Table 
2) were significantly higher than those of control $(P<0.01$ and $P<0.05)$. Also, serum neopterin levels in replicative group were higher than in nonreplicative groups $(P<$ $0.05)$. There are no difference between men and women. The levels of serum neopterin in 30 control and 30 replicative and 25 nonreplicative patients were shown in Table 1 and 2 and Figure 1. In this study, when the cut-off value was set as $8.7 \mathrm{nmol} / \mathrm{L}, 21$ out of 30 replicative patients, 11 out of 25 nonreplicative patients and 11 out of 30 controls' neopterin values were higher than this level ( $\mathrm{p}<$ $0,05)$. On the other hand, when the cut-off value was set as $10 \mathrm{nmol} / \mathrm{L}, 18$ out of 30 replicative, 8 out of 25 nonreplicative and 5 out of 30 control subjects' neopterin values were found to be higher than this point $(\mathrm{p}<0,05)$ (Table 2).

Neopterin levels in nonreplicative carriers did not differ from those of control. When HBV-DNA levels were categorized according to copy values as picogram, neopterin levels were not correlated HBV-DNA levels (Table 4).

In the nonreplicative group, except for one patient, all the patients' HBeAg were negative and anti-HBe were positive. That particular patient's HBeAg was positive and anti-HBe negative. In the replicative group, 23 out of 30 patients have positive HBeAg and negative anti-HBe; 7 out of 30 patients have negative HBeAg and positive anti-HBe.

The averages of ALT levels were in reference limits according to our laboratory for all groups. The mean of serum ALT levels were $44 \pm 14,29 \pm 11$ and $26 \pm 7.5 \mathrm{IU} / \mathrm{L}$ in the replicative, nonreplicative carriers and control group, respectively. Serum ALT levels were not different according to interquartile range of serum neopterin (Table 3).

\section{Discussions and conclusion}

Immune defense against virus infection involves both nonspecific and antigen-specific phases [1]. The stimulation of the cellular immunity associated with macrophage activation causes an increase of neopterin in the urine, serum and other body fluids. Neopterin has been reported as the indicator of local macrophage activity in different body fluid. Neopterin secretion is found to increase in patients suffering from viral, bacterial or parasitic infec- tions and with immune and autoimmune diseases $[2,3,10]$. Neopterin is considered as a parameter of immun activation and inflammation [11]. Elevation of neopterin levels in AIDS and tumor patients correlates with the severity of the disease [12-14].

The measurement of HBV DNA levels in serum has become an important tool for the identification of individuals with high levels of viral replication that might benefit from antiviral therapy, monitoring of patients on therapy, and prediction of whether antiviral therapy will be successful. Several molecular approaches, commercially available tests, have been used to quantity serum HBV DNA levels [15]. Hybrid capture method was used in this study to assess the viral load of the patient group. In this study, if patients have $>5 \mathrm{pg} / \mathrm{ml}$ viral load they are called replicative; if the patients have not HBV DNA they are called nonreplicative. In the present study serum neopterin levels were examined in replicative HBV carriers and nonreplicative HBV carriers. In the replicative HBV carriers, the neopterin levels were found to be elevated. Serum neopterin levels in the replicative group were significantly higher than those of control group $(P<0.01)$.

Neopterin concentrations in serum show a slight increase with age but not sex dependent difference $[2,10,16]$. As the upper limit of serum neopterin in healthy controls which are age between 19-75 years, $8.7 \mathrm{nmol} / \mathrm{L}$ are accepted in some studies[2,10]. The cut-off value of our kit is $10 \mathrm{nmol} / \mathrm{L}$. We estimated of $83,3^{\text {th }}$ percentile of neopterin values of controls as $<10 \mathrm{nmol} / \mathrm{L}$. In present study, $63,3^{\text {th }}$ percentile of neopterin values of controls were estimated as $<8.7 \mathrm{nmol} / \mathrm{L}$ Therefore we decided that our cut-off value as $10 \mathrm{nmol} / \mathrm{L}$.

It is reported that clinically healthy HBsAg carriers have normal neopterin levels [2]. Daito et al [17] have reported that neopterin levels and rates of abnormal serum and urinary values in asymptomatic HBsAg carriers did not differ from those of controls, but in the acute hepatitis, neopterin levels were significantly higher than those normal subjects. Serum neopterin levels in patients with B viral chronic liver disease were significantly higher than those in asymptomatic HBsAg. Kiliç et al [18] have reported that

Table I: Serum neopterin levels in replicative, non replicative carriers and control

\begin{tabular}{lccccc}
\hline Groups & \multicolumn{3}{c}{ Neopterin Levels (nmol/L) } \\
\cline { 2 - 5 } & Mean & Median & Standard Deviation & Minimum & Maximum \\
\hline Replicative $(n=30)$ & 14.5 a, b & 11.5 & 10.0 & 4.2 & 41 \\
Non-replicative $(n=25)$ & 8.8 & 8.0 & 4.3 & 2.1 & 4.0 \\
Controls $(n=30)$ & 7.1 & 7.5 & 2.2 & 12 \\
\hline
\end{tabular}

a: $P<0.01$ vs controls, b: $P<0.05$ vs nonreplicative 
Table 2: Rates of Abnormal Serum Neopterin Levels in Various Groups

\begin{tabular}{|c|c|c|c|c|c|}
\hline \multirow[t]{3}{*}{ Groups } & \multirow{3}{*}{ No of cases } & \multicolumn{4}{|c|}{ Abnormal Serum Levels } \\
\hline & & \multicolumn{2}{|c|}{$\geq 8,7 \mathrm{nmol} / \mathrm{L}$} & \multicolumn{2}{|c|}{$\geq 10 \mathrm{nmol} / \mathrm{L}$} \\
\hline & & $\mathrm{n}$ & $\%$ & $\mathrm{n}$ & $\%$ \\
\hline Replicative & 30 & $21^{a}$ & 70 & $18^{\mathrm{a}}$ & 60 \\
\hline Non-replicative & 25 & 11 & 44 & 8 & 32 \\
\hline Controls & 30 & 11 & 36,6 & 5 & 16,6 \\
\hline
\end{tabular}

a: $P<0.05$ vs controls

neopterin levels were significantly increased in HBV carriers without viral replication as compared with that of controls. In another study, the levels of serum neopterin in patients with hepatic cirrhosis have been found significantly higher than the control groups. In cirrhotic patients neopterin concentrations were not affected by the etiology of liver disease [19]. In HCV positive patients, serum neopterin levels were measured in several studies [20-22].

Grüngreiff et al [21] have found that elevated concentrations of the neopterin in patients with chronic hepatitis $\mathrm{C}$ infection before therapy $(10.79 \pm 5.51 \mathrm{nmol} / \mathrm{L})$ compared to healthy controls $(1.25 \pm 0.26 \mathrm{nmol} / \mathrm{L})$ but, the difference was found negligible between responders and nonresponders during in the IFN therapy. The end of therapy mean concentration was the lowest in partial responders, and highest in non-responders. Neopterin levels in healthy control in their study were lower than our study. We can speculate that these differences may be due to

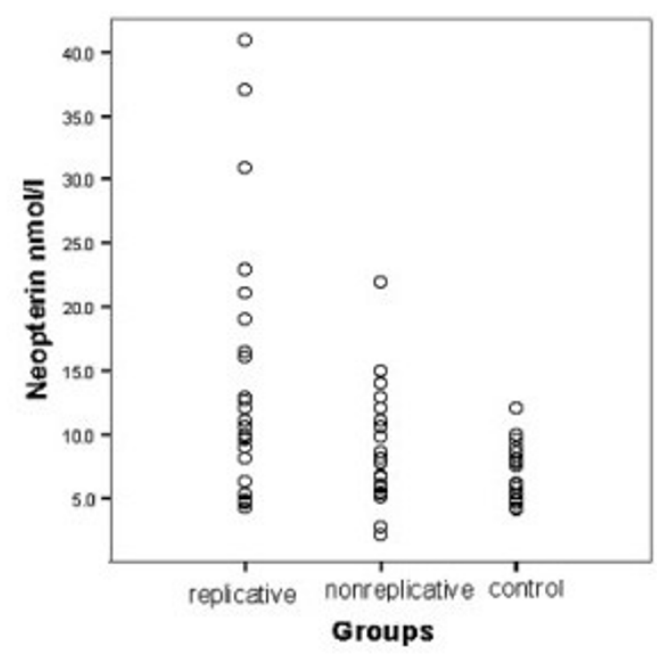

\section{Figure I}

Serum neopterin levels in patients with replicative, nonreplicative and control. using different kits. Leonardi et al [22] found that serum neopterin was higher in HCVAb positive than in HCVAb negative patients. In another study, neopterin increased from 1 to 2 weeks after the start of IFN- $\gamma$ in HCV-RNA positive patients [20].

In this study, there was no correlation between neopterin concentrations and HBV DNA levels in the replicative group. It can be concluded that the neopterin level could be related to the presence of the replication and not to the quantity of the viral load. As the neopterin is produced as a result of macrophage activation, neopterin level found in this study to be higher in replicative group as compared to nonreplicative and the control groups indicates that cellular immune response continues in replicative group. However, in this study, absence of increase in neopterin serum levels in all replicative individuals, and the absence of relation between the increase in neopterin levels and the viral load, can derive from different immune response of the host. Even though several other factors may cause neopterin increase, in this study the rise of neopterin levels until to $70 \%$ of the replicative group seem very significant.

In conclusion, in the Hepatitis B infected carriers, elevated neopterin levels may be an indicator of the presence of replication. Further studies may need to be carried out to establish the relation between the increase in serum neopterin levels and virus replication in Hepatitis B carriers.

\section{Competing interests}

The author(s) declare that they have no competing interests.

\section{Authors' contributions}

IK participated in its design and coordination of the study, and co-drafted the manuscript. MD participated in the analysis and interpretation of the data and co-drafted the manuscript NC participated in the analysis and interpretation of the data MY participated in interpretation of the data. SD participated in interpretation of the data and Codrafted the manuscript. 
Table 3: Serum ALT levels according to interquartil range of serum neopterin

\begin{tabular}{lcccccc}
\hline Neoptein Quartile & $\mathrm{n}$ & Mean & Std. Deviation & Median & Minimum & Maximum \\
\hline 1 & 21 & 35.85 & 14.31 & 29 & 13 & 61 \\
2 & 22 & 30.04 & 11.79 & 28.5 & 14 & 62 \\
3 & 25 & 31.52 & 13.77 & 25.0 & 18 & 63 \\
4 & 17 & 38.17 & 14.54 & 35.0 & & 14 \\
\hline
\end{tabular}

$p>0.05$

Table 4: Serum neopterin levels according to HBV DNA in replicative group

\begin{tabular}{lcccccc}
\hline \multicolumn{1}{c}{ HBVDNA $(\mathrm{pg})$} & Mean & $\mathrm{n}$ & Std. Deviation & Median & Minimum & Maximum \\
\hline $5-100$ & 17.7 & 8 & 10.2 & 14.0 & 9.5 & 41.0 \\
$101-500$ & 12.7 & 7 & 9.1 & 10.5 & 4.0 & 31.0 \\
$501-1000$ & 17.8 & 2 & 18.7 & 17.8 & 4.6 & 31.0 \\
$1000<$ & 12.3 & 13 & 10.1 & 8.0 & 3.2 & 37.0 \\
\hline
\end{tabular}

\section{References}

I. Jung MC, Diepolder HM, Spengler U, Wierenga EA, Zachoval R, Hoffmann RM, Eichenlaub D, Frösner G, Will H, Pape GR: Activation of a heterogeneous hepatitis $B$ (HB) core and e antigen-specific CD4+ T-cell population during seroconversion to anti-HBe and anti-HBs in hepatitis B virus infection. J Virology 1995 , 69:3358-3368

2. Fuchs D, Weiss G, Reibnegger G, Wachter $H$ : The role of neopterin as a monitor of cellular immune activation in transplantation, inflammatory, infectious, and malignant diseases. Crit Rev Clin Lab Sci 1992, 29:307-34I.

3. Fuchs D, Weiss G, Wachter H: Neopterin, biochemistry and clinical use as a marker for cellular immune reactions. Int Arch Immunol 1993, I 01: I-6.

4. Azumagawa K, Suziki S, Tanabe T, Wakamiya E, Kawamura N, Tamai $\mathrm{H}$ : Neopterin, biopterin and nitric oxide concentrations in the cerebrospinal fluid of children with central nervous system infections. Brain \& Development 2003, 25:200-202.

5. Adamik B, Kübler-Kielb J, Golebiowska B, Gamian A, Kübler A: Effect of sepsis and cardiac surgery with cardiopulmonary bypass on plasma level of nitric oxide metabolites, neopterin, and procalcitonin: correlation with mortality and postoperative complications. Intensive Care Med 2000, 26:I259-I 267.

6. Tanaka J, Koshimura K, Tsumori M, Murakami Y, Kato Y: Monitoring of urine nitric oxide (NO) related substrates and immunological competence in hematological malignancy. Acta Biochim Polonica 2002, 49:227-232.

7. Kallio R, Surcel HM, Bloigu A, Syrjala H: Admission neopterin and interleukin 12 concentrations in identifying infections in adult cancer patients. Cytokine 200I, I 3:37I-374.

8. Idilman R, Arat M, Soydan E, Törüner M, Soykan I, Akbulut H, Arslan Ö, Özcan M, Türkyılmaz AR, Bozdayi M, Karayalçın S, Van Thiel DH, Özden A, Beksaç $M$, Akan $H$ : Lamuvidine prophylaxis for prevention chemotherapy-induced Hepatitis $B$ Virus reactivation in Hepatitis B carriers with malignancies. J Viral Hepat 2004, I I:|4|-|47.

9. Ben-Ari Z, Mor E, Papo O, Kfir B, Sulkes J, Tambur AR, Tur-Kaspa R, Klein T: Cytokine gene polymorphisms in patients infected with hepatitis B virus. Am J Gastroenterol 2003, 98: I 44- I 50.

10. Müller MM, Curtius HC, Herold M, Huber $\mathrm{CH}$ : Neopterin in clinical practice. Clinica Chimica Acta 1991, 201:I-16.

I I. Fahey JL, Aziz N, Spritzler J, Plaeger S, Nishanian P, Lathey JL, Seigel J, Landay AL, Kilarui R, Schmitz JL, White C, Wara DW, Akridge R, Cutili J, Douglas SD, Reuben J, Shearer WT, Nokta M, Polland R, Schooley R, Asthana D, Mizrachi Y, Waxdal M: Need for an external proficiency testing program for cytokines, chemokines, and plasma markers of immune activation. Clin Diagn Lab Immunol 2000, 7:540-548.

12. Fuchs D, Shearer MG, Boswell RN, Clerici M, Reibnegger G, Werner $E R$, Zajac RA, Wachter $H$ : Increased serum neopterin in patients with HIV-I infection is correlated with reduced in vitro interleukin-2 production. Clin Exp Immunol 1990, 80:44-48.

13. Aziz N, Nishanian P, Fahey JL: Levels of cytokines and immune activation markers in plasma in human immunodeficiency virus infection: quality control procedures. Clin Diagn Lab Immunol 1998, 5:755-76I.

14. Shi M, Taylor JM, Fahey JL, Hoover DR, Munoz A, Kingsley LA: Early levels of CD4, neopterin, and beta 2-microglobulin indicate future disease progression. J Clin Immunol 1997, I 7:43-52.

I5. Niesters HGM, Krajden M, Cork L, Medina M, Hill M, Fries E, Osterhaus ADME: A multicenter study evaluation of the digene hybrid capture II signal amplification technique for detection of hepatitis B virus DNA in serum samples and testing of EUROHEP standards. J Clin Microbiol 2000, 38:2I 50-2I 55.

16. Sack U, Burkhardt U, Borte M, Schadlich H, Berg K, Emmrich F: Agedependent levels of select immunological mediators in sera of healthy children. ClinDiagn Lab Immunol 1998, 5:28-32.

17. Daito K, Suou T, Kawasaki H: Clinical significance of serum and urinary neopterin levels in patients with various liver diseases. Am J Gastroenterol 1992, 87:47I-476.

18. Kiliç D, Boyunağa H, Kaygusuz S, Akgül EÖ, Rashed MA, Kenar L, Erbil K, Kutluay T: Neopterin levels in nonreplicative HBV carriers. Hepatology Research 2002, 24:18-22.

19. Fernandez E, Rodrigo L, Riestra S, Garcia S, Gutierrez F, Ocio G: Adenosine deaminase isoenzymes and neopterin in liver cirrhosis. J Clin Gastroenterol 2000, 30:181-186.

20. Kumashiro R, Ide T, Sasaki M, Murashima S, Suziki H, Hino T, Morita Y, Miyajima I, Ogata K, Tanaka E, Yoshida H, Tanikawa K, Sata M: Interferon- $\gamma$ brings additive anti-viral environment when combined with interferon- $\alpha$ in patients with chronic hepatitis C. Hepatology Research 2002, 22:20-26.

21. Grüngreiff K, Reinhold D, Ansorge S: Serum concentrations of sIL-2R, IL-6, TGF- $\beta$ I, neopterin, and zinc in chronic hepatitis C patients treated with interferon-alpha. Cytokine 1999, I I:1076-1080.

22. Leonardi S, Avola E, Sciacca A, Di Gregorio F, Musumeci S: Neopterin as a marker of $\mathbf{C}$ hepatitis in thalassaemia major. J Pediatr Gastroenterol 1991, | 2:3 15-3 I8.

\section{Pre-publication history}

The pre-publication history for this paper can be accessed here:

http://www.biomedcentral.com/1471-2334/6/157/pre pub 